\title{
IN-VITRO SCREENING OF THEAFLAVIN AND GINKGETIN ON A549 LUNG CANCER CELL LINE
}

\author{
Mr. Nisarg Vyas \\ Mr. Ram Tej Verma
}

\begin{abstract}
Cancer is a complex, multi-gene, multi-step disease occurring as a result of a sequential accumulation of genetic and epigenetic changes. Death due to cancer rank second among all cause of death globally. Dysregulation of signaling pathway e.g. HGF/c-MET which were otherwise activated during embryonic development contributes to malignant transformation and metastasis in later phase of life. Phytochemicals due to their safety, low toxicity, and general availability are either taken as supplement or through dietary sources for cancer chemoprevention or supportive agent during the treatment of cancer. The present study therefore aim to screen in-silico inspired c-MET antagonist Theaflavin \& Ginkgetin in-vitro on against A549 cell line along with their antiangiogenesis effect on chick embryo model.
\end{abstract}

Keywords: CMET, Theaflavin, Ginkgetin, Anticancer Natural Product

\section{Introduction}

Cancer, the malignant neoplasm resulting from a progressive accumulation of genetic aberrations and epigenetic changes that escape's host's immune system. It is a multi-gene, multi-step disease that originates and proliferates clonally with consecutive rounds of mutation and selective expansion (Herceg Z \& Hainaut P, 2007; Baylin SB and Jones PA, 2016). In later stage a set of cancer cells invades into surrounding tissue and manage to migrate to distant organs through vascular channel. Different signaling pathways and variety of molecular mechanisms e.g. intracellular trafficking, cytoskeletal reorganization are co-ordinated during the process of cell migration and invasion. It has been reported that hepatocyte growth factor (HGF) is a major inducer of cancer cell migration and invasion through cytoskeleton assembly and 
reorganization during the process of metastasis (Toppmeyer DL et al, 2003). MET is normally expressed on the surface of cells with an epithelial origin, while expression of HGF/SF is from cells with mesenchymal origin. Binding of HGF to MET receptor induces receptor dimerization leading to its activation and initiates a downstream signaling cascade (Demkova, $L$ and Kucerova, L, 2018). Under normal physiological conditions the hepatocyte growth factor (HGF) and its receptor, the MET transmembrane tyrosine kinase (CMET) has been associated with embryogenesis, morphogenesis, organ regeneration, wound healing and cancer (Ricci G et al, 2006; Wang $\mathrm{H}$ et al, 2020). This ligand-mediated activation of MET is a key contributor for invasion, metastasis, and resistance to therapy in various cancers. Deregulation of the HGFcMET axis is also implicated in malignant transformation and progression through modulation of epithelial-mesenchymal transition (Renzo MF et al, 2003; Ribatti D et al, 2001). The growth and metastasis of malignant cell populations also rely on the development of microvessels to grow and metastasize (Lambert-AW, 2017; Farnsworth et al., 2014). Several studies have been published concerning angiogenesis inhibitors e.g. Sunitinib, Marimastat and TNP-470 with their limitations and toxicities (Herbst RS, 2002).

Phytochemicals are traditionally used since ancient times to cure many diseases including cancer. Survey of chemotherapeutic agents and their sources indicates that over $60 \%$ of approved drugs are derived from natural compounds (Khoogar $R$ et al, 2016). Natural products e.g. taxel and vincristine are still in use for treatment of various cancers. Several naturally occurring phytochemicals e.g. Hesperidin, silymarin, EGCG, curcumin, capsaicin, which are obtained from diet, serves as cancer chemopreventive agents (Andriani F et al, 2006; Hu X et al, 2020). The authours have already established in-silico evidence of Theaflavin and Ginkgetin as potent binding ligand on C-MET (Vyas et al, 2019). Besides receptor mediated signalling angiogenesis also plays a significant role in tumor progression (Zhang et al, 2018; Zhou Q et al, 2003). Hence, inhibiting angiogenesis may also provide significant advantage over presently available anti- cancer therapies. Therefore, cMET inhibition along with inhibiting angiogenesis using potent phytopharmaceutical seems to be a promising therapeutic strategy for majority of cancers. 


\section{Material \& Methods}

On the basis of results obtained from our in-silico study we shortlisted Theaflavin, Ginkgetin for in-vitro screening on A549 lung cancer cell line which expresses cMET (Vyas et al 2019).

Chemicals and other reagents: Theaflavin-3-gallate and Ginkgetin were purchased from Sigma (USA). For in vitro studies, theaflavin-3-gallate and Ginkgetin were dissolved in dimethyl sulfoxide (DMSO) to create a stock solution $(0.1 \mathrm{~mol} / \mathrm{L})$, which was stored at $-20^{\circ} \mathrm{C}$ until analysis. The working solutions were prepared from the stock solution by further diluting it with culture media to yield the desired concentrations. Control cells were treated with an equal volume of vehicle. The DMSO concentration was kept below $0.1 \%$ in cell culture and did not show any noticeable effect on cell growth or cell death. DMEM \& fetal bovine serum (FBS), penicillinstreptomycin were obtained from GIBCO, NY.

Culture of Cell line: Human lung cancer cell line A549 was obtained from the National Center For Cell Science,(NCCS Pune, Maharashtra) and cells were grown in DMEM media at $37^{\circ} \mathrm{C}$ in a humidified atmosphere containing $5 \% \mathrm{CO}_{2}$. Cells were sub-cultured by treating them with Trypsin-EDTA solution in Phosphate buffer saline (PBS) prior to plating.

Cell proliferation study on A549 cell line using WST-1 assay: Culture A549 cell line was grown till $80 \%$ confluency and then trypsinized cells were plated in 96 well plate at a concentration of $5 \times 10^{4}$ cells /well in a final volume of $100 \mu \mathrm{l} /$ well culture medium. Cells were allowed to acclimatize in culture medium for $24 \mathrm{~h}$ at $+37^{\circ} \mathrm{C}$ and $5 \% \mathrm{CO} 2$. Known amount of Ginkgetin \& Theaflavin were added with increasing concentration $(0,5,10,20,40,80,100$ \& $150 \mu \mathrm{M}$, eight wells per concentration) in triplicate. Control wells were not having phytochemical but with equal volume of plain media. 10 $\mathrm{\mu l}$ WST-1 Reagent to each well. The stable tetrazolium salt WST-1 is cleaved to a soluble formazan by the succinate-tetrazolium reductase system (EC 1.3.99.1) which belongs to the respiratory chain of the mitochondria, and is only active in metabolically intact cells. This bioreduction is largely dependent on the glycolytic production of $\mathrm{NAD}(\mathrm{P}) \mathrm{H}$ in viable cells. Therefore, the amount of formazan dye formed directly correlates to the number of metabolically active cells in the culture. Cells were incubated with the WST-1 reagent for 4 hours. The reaction was stopped by adding 1\% Triton X-100/ $0.1 \%$ SDS (final concentration) for $5 \mathrm{~min}$ at $+37^{\circ} \mathrm{C}$. Microtitre plate was shaken thoroughly for $1 \mathrm{~min}$ on a shaker. 
The solubilized formazan dye is quantitated with an ELISA reader at $450 \mathrm{~nm}$ and $600 \mathrm{~nm}$ as reference wavelength. The measured absorbance directly correlates to the number of viable cells when plotted against the standard. The cells viability was assessed as the percent values compared with untreated control group, IC50 (the concentration required to induce 50\% cells growth inhibition) was determined by interpolation from dose response curves using Graphpad prism5 (Venepalli NK et al, 2013).

Wound healing Assay: Cells were seeded $(2 \times 104$ cells/well) in 6-well plates and incubated to form a confluent monolayer at $37^{\circ} \mathrm{C}$ for $24 \mathrm{hrs}$. After incubation, old media was removed and the monolayer of the cells was scraped with a sterile $200-\mu \mathrm{L}$ tip to form a scratch. All the wells were washed with plain media to remove the debris following washing with $1 \mathrm{ml}$ of growth media and then replaced with media containing Theaflavin and Gingketin. Pictures were taken using an inverted microscope at 0, 6, 12 and $28 \mathrm{hrs}$. (Jing Li, et al, 2012).

Apoptosis Assay: Furthermore, results were established using acridine orange (AO) and propidium iodide (PI) double staining to observe apoptotic effect of Theaflavin and Gingketin. Cells were seeded on the coverslip in 6-well plates for $24 \mathrm{hrs}$ at $37^{\circ} \mathrm{C}$ in incubator. After that, cells were exposed to Theaflavin and Gingketin at above mentioned concentrations for next 24 hrs. Cells were washed with PBS and then stained with $5 \mu$ l of fluorescent dye containing AO (10 $\mu \mathrm{g} / \mathrm{mL})$ and $\mathrm{PI}(10 \mu \mathrm{g} / \mathrm{mL})$. Stained coverslip was placed onto a glass slide and observed under fluorescent microscope (Khoogar R et al, 2016).

Gene Expression Study: Signaling pathway suggested regulatory role of cMET on downstream CMYC and CD44 gene expression. Therefore, expression levels of these two genes may predict the downstream regulation of pathway after supplementation of selected phyto-pharmaceuticals on cell line. RNA was isolated from cells exposed to Theaflavin and Ginkgetin using TRIZOL method. RNA extracted from unexposed cells were treated as control. Isolated RNA was quantified on Qubit and $1 \mu \mathrm{g}$ of RNA was reverse transcribed to cDNA for further expression studies. Realtime PCR based expression of CMYC and CD44 was carried out using gene specific primers with CYBR green chemistry in Quantstudio-5 machine (LifeTechnology). The PCR cycling conditions were as follows: denaturation, $94^{\circ} \mathrm{C}$ for $30 \mathrm{sec}$; annealing, $60^{\circ} \mathrm{C}$ for $60 \mathrm{sec}$; extension, $68^{\circ} \mathrm{C}$ for $2 \mathrm{~min}$. The number of cycles used depended upon the nature of the experiment; in general, 30 cycles were performed. Relative fold change $(\Delta \Delta C T)$ in the 
expression level of these two genes were quantified (Wanda RF et al, 2001). c-myc forward primer: 5'-TAC CCT CTC AAC GAC AGC AG-3'; c-myc reverse primer: 5'-TCT TGA CAT TCT CCT CGG TG-3'; $\beta$-actin forward primer: 5'-TCA CCC ACA CTG TGC CCA TCT ACG A-3'; $\beta$ actin reverse primer: 5'CAG CGG AAC CGC TCA TTG CCA ATG G-3'; CD44 forward primer: 5'-CTGCAGGTATGGGTTCATAG-3'; reverse primer-5'ATATGTGTCATACTGGGAGGTG-3'.

Western blot analysis: Cells were lysed with EBC buffer (50 mM Tris ( $\mathrm{pH} 7.5), 150 \mathrm{mM} \mathrm{NaCl}$, 0.5\% NP-40, $1 \mathrm{mM}$ complete protease inhibitors (Roche Diagnostics), and $1 \mathrm{mM}$ phosphatase inhibitor mixture III (Sigma-Aldrich). The protein concentration of cell lysates utilized for western blot analysis was estimated using a Bio-Rad protein assay (Hercules, CA, USA). Western blotting was performed by SDS-PAGE followed by transferring the proteins onto nitrocellulose membranes .Protein concentration of $30 \mathrm{mg}$ from each samples were loaded onto $10 \%$ SDS -PAGE gels and electro-transferred on to PVDF membranes. To restrict nonspecific binding the membranes were then blocked with $5 \%$ nonfat dry milk in buffer, and probed with primary antibodies of $\beta$-actin, AKT, pAKT (Santa Cruz Biotechnology, Inc., Santa Cruz, CA, USA) overnight at $4{ }^{\circ} \mathrm{C}$. After incubation with secondary antibody, the blots were visualized by an enhanced chemiluminescence detection kit (Sigma-Aldrich). Quantitative analysis of blots was carried out using the Bio-Rad gel documentation system. $\beta$-actin was used as an internal control (Elkhadragy L et al, 2018).

\section{Angiogenesis inhibition assay}

Chick embryo Chorio-Allantoic Membrane assay: Fertilized white chicken eggs were obtained from Local farm of Ahmedabad and were incubated at $37.5^{\circ} \mathrm{C}$ with $60 \%$ humidity in a custom made incubator. The outer surface of the shell was cleaned with $1 \%$ germicidal solution. The CAM assay was conducted as described by Chan T et al (2005). On the 9th day, the shell area beyond the air chamber of the egg was marked. Small windows $(10 \times 10 \mathrm{~mm} 2)$ were opened in the center of the marked area using a scalpel and microdrill. The egg shells were then opened with sterile forceps. The sample solution [IC50 concentration of experimental compounds and the negative control $0.3 \mu \mathrm{l}$ DMSO in $30 \mu \mathrm{l}$ phosphate-buffered saline $(\mathrm{pH} 7.4)$ ], were then placed directly onto the CAM through the egg shell openings. The windows were then sealed with transparent shallow tape with proper labelling and were kept back in the incubator at $37.8^{\circ} \mathrm{C}$ and $60 \%$ humidity. The egg shells were then cut carefully along the axis of the median line and the 
content was discarded after $48 \mathrm{~h}$. The CAM vasculature around the egg shell windows was observed and the treated area was defined as the area on the CAM where the compounds or control DMSO were attached. Digital images were captured at room temperature with a camera. The images were visually analyzed and the number of every treatment condition ( 5 embryos per condition) in which the vessels had become less dense around the treated area was recorded as a positive number (R. Amaani and S. Dwira, 2018).

\section{RESULTS}

\section{Cell proliferation study on A549 cell line}

The $\mathrm{IC}_{50}$ values of A549 cells treated with Theaflavin, Ginkgetin and cisplatin were assessed by WAT-1 assay at $24 \mathrm{~h}$. The results showed that exposure of NSCLC cell lines (A549) to a range of Theaflavin $(38.51 \mu \mathrm{M})$, Ginkgetin $(29.53 \mu \mathrm{M})$ and cisplatin $(\leq 22 \mu \mathrm{M})$ concentrations resulted in $\mathrm{IC}_{50}$ values of 38.51 and $29.53 \mu \mathrm{M}$ and 22.23 , respectively.

A

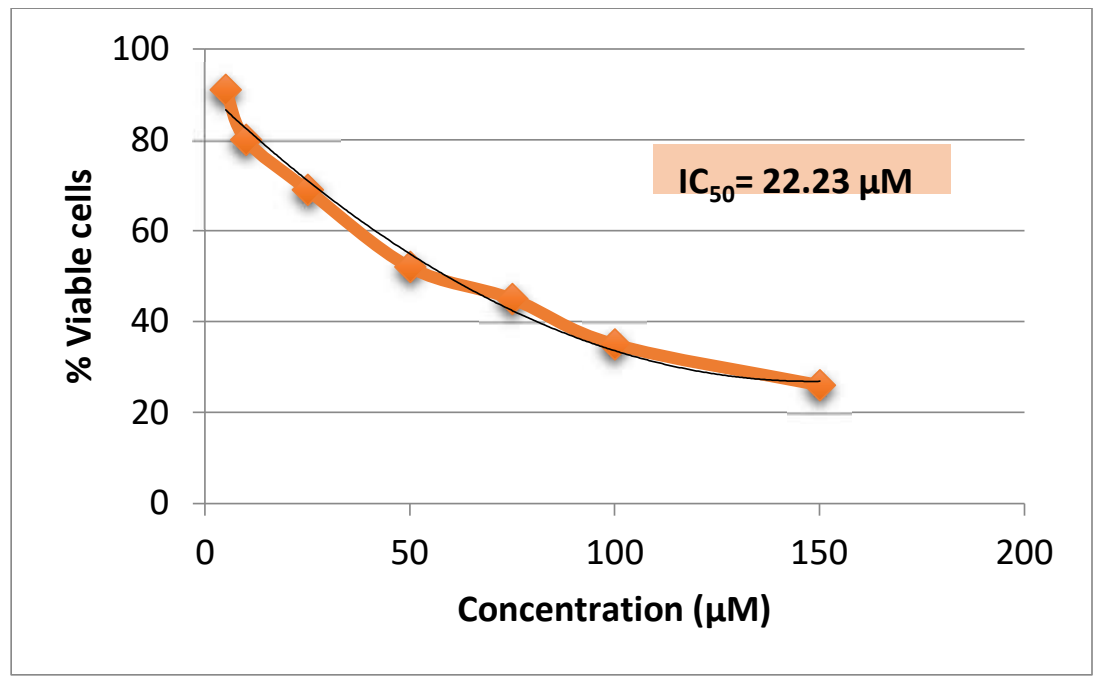


Vyas \& Mr. Ram Tej Verma / Page 110-126

B

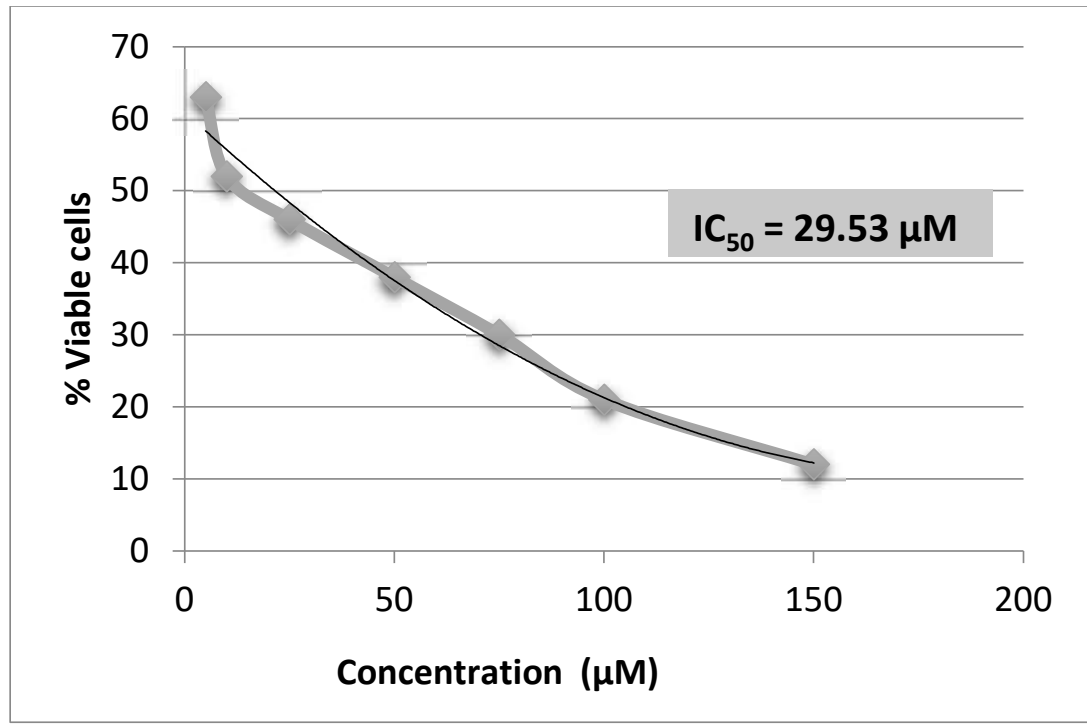

C

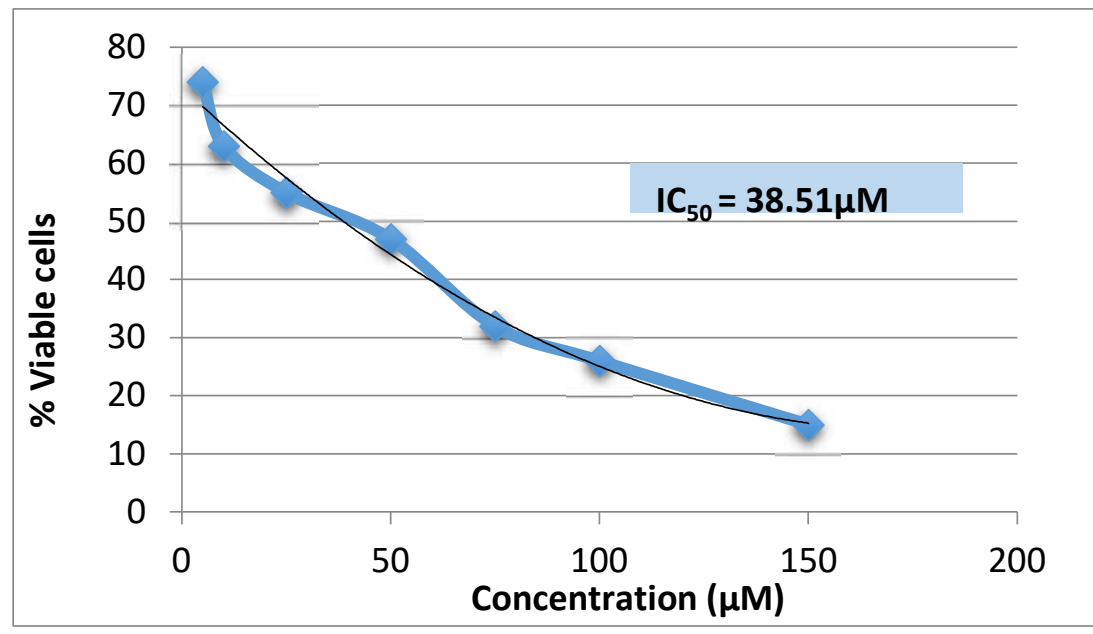

Figure 1 (A-C): IC 50 values of Theaflavin, Gingketin and cisplatin in A549 cell ine by WST1 assay. The viability of A549 cells were measured after $24 \mathrm{hr}$ treatment with varios concentration of Cisplatin (A), Ginkgetin (B) and Theaflavin (C).

\section{Wound healing Assay}

A wound healing assay / migration assay is a laboratory technique used to study cell migration and cell-cell interaction. This is also called a scratch assay because it is done by making a scratch on a cell monolayer and capturing images at regular intervals by time lapse microscope. A typical scratch wound healing assay, a "wound gap" in a cell monolayer is created by scratching, and the "healing" of this gap by cell migration and growth towards the center of the gap is monitored and often quantitated. Factors that alter the motility and/or growth of the cells can lead to increased or decreased rate of "healing" of the gap Migration of A549 cells was 
studied by wound healing assay, and results established that cell migration in A549cell lines was statistically decreased in the presence of Theflavin and Ginkgetin treatment at 0, 6, 12, and 24 (Figure 2). Gap was completely sealed after $48 \mathrm{hrs}$ when treated with TGF- $\beta$, suggesting its potential in cell migration during metastasis; while it was observed that Theflavin and Ginkgetin prevented the migration of cells, suggesting the plausible role of Theflavin and Ginkgetin to inhibit the cell migration eventually inhibiting metastasis.

Scratch Wound healing Assay on A549 Cell line

A

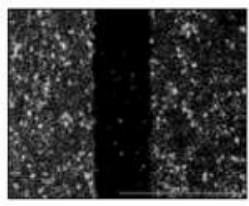

B

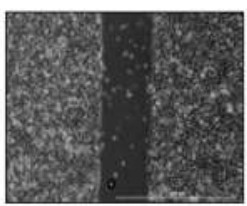

$\mathrm{C}$

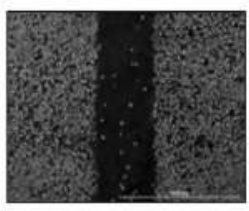

D

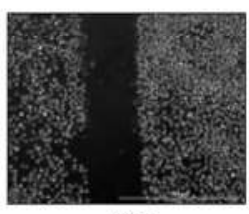

$0 \mathrm{hr}$
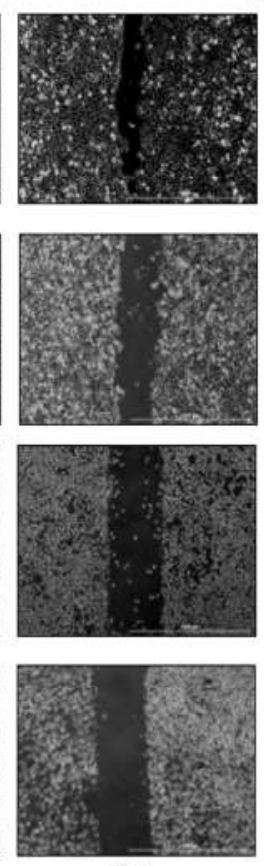

$6 \mathrm{hr}$
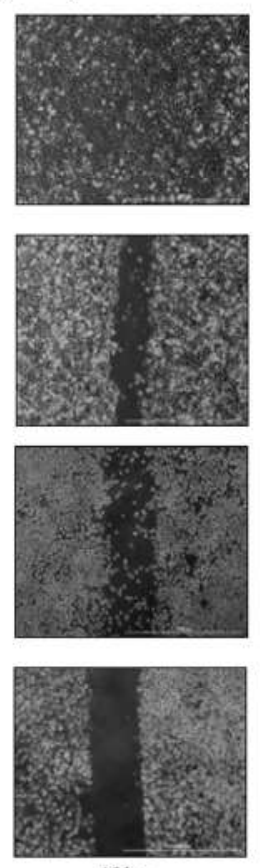

$12 \mathrm{hr}$

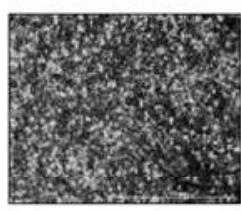

No Drug Control

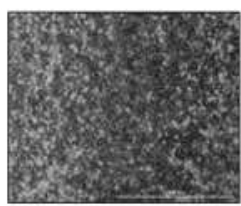

Theaflavin

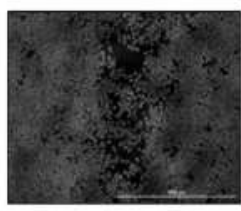

Ginkgetin

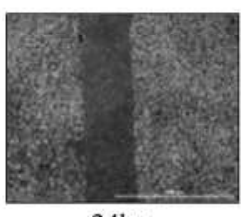

$24 \mathrm{hr}$
Gemcitabine Control

Figure 2 (A-D): Scratch wound healing assay result shown as time lapse images at 0, 6, 12 \& 24 hr interval. Lane A. No Drug Control; Lane B. Theflavin Exposure; Lane C. Ginkgetin Exposure; Lane D. Gemcitabine as control drug.

\section{Quantification of Apoptosis by Acridine Orange and Propidium lodide Double Staining}

Furthermore, results were established with $\mathrm{AO}$ and $\mathrm{PI}$ double staining to distinguish viable cells from early apoptotic, late apoptotic and necrotic cells. 200 cells were differentially and randomly scored under the fluorescence microscope. Results exposed that Theflavin and Ginkgetin had the potential to trigger morphological features that relate to apoptosis and death in timedependant manner (Figure 3). 


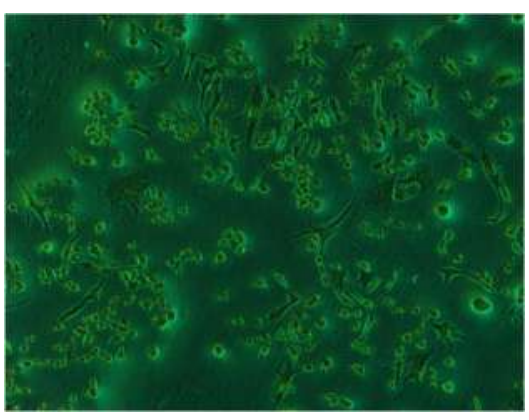

(a) Control

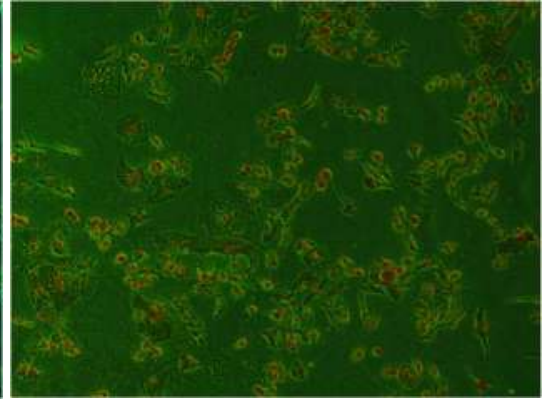

(b) Theaflavin

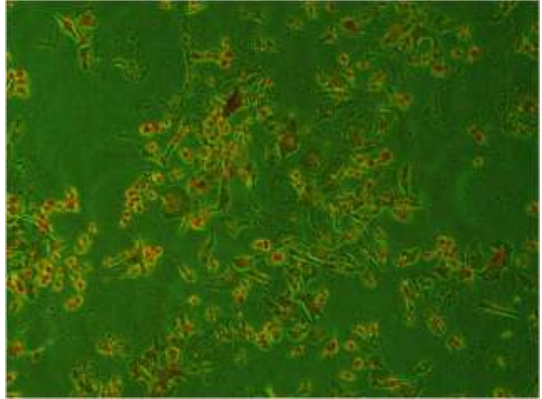

(c) Ginkgetin

Figure 3: $(a, b, c)$ Fluorescence Microscopic image showing number of apoptotic cells after exposure of Theaflavin and Ginkgetin.

\section{Gene Expression Study}

Also, we investigate the inhibitory potential of Theaflavin and Ginkgetin on mRNA expression of CMYC and CD44. Oure result revealed that the CMYC and CD44 expression was observed to be decreased significantly $(p<0.0001)$ after the treatment of Theaflavin and Ginkgetin.

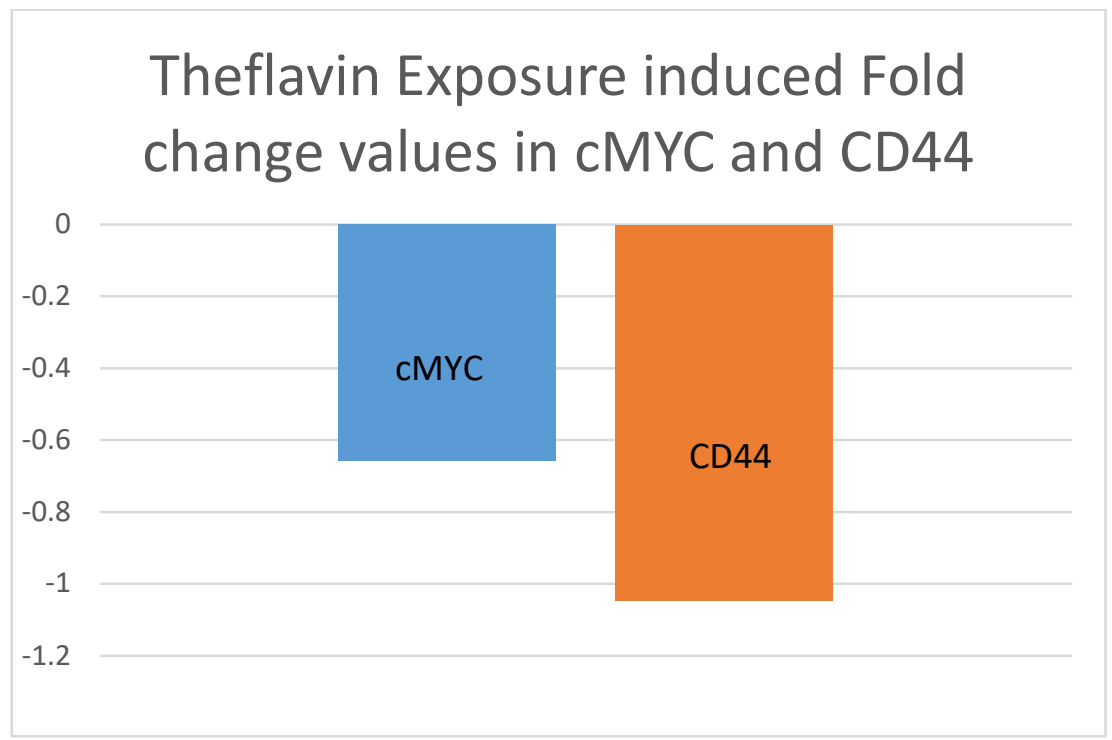


Vyas \& Mr. Ram Tej Verma / Page 110-126

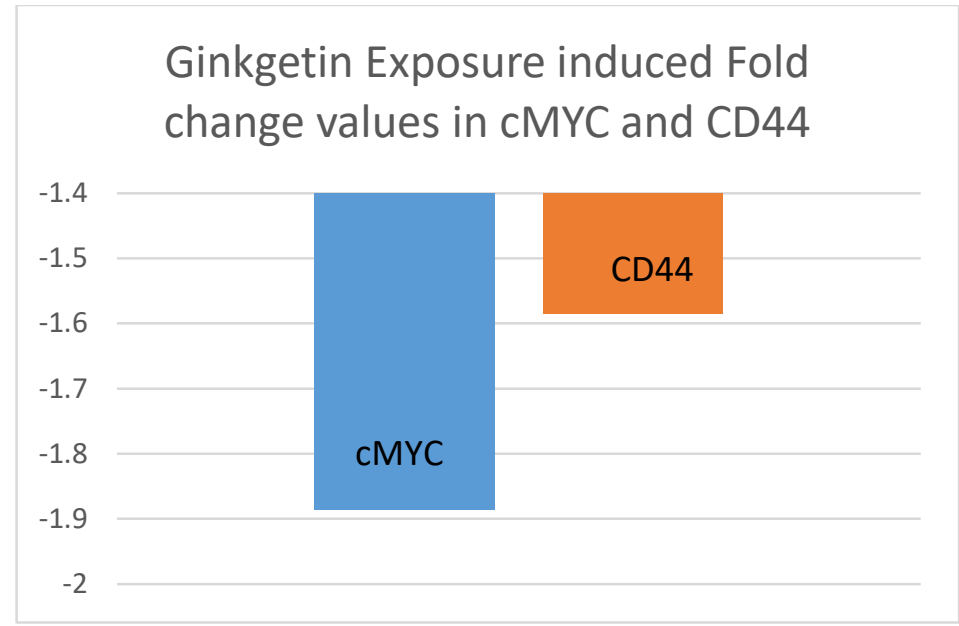

Figure 4: Ginkgetin showed around 76.9 and 38.4 fold down regulation in cMYC and CD44 gene expression as compared to unexposed cells. Similarly Theflavin showed 4.5 and 11.1 fold down regulation of these genes respectively.

\section{Inhibitory Effect of Theaflavin and Ginkgetin on Signaling Pathways}

Western blot as shown in Fig-5 reveals significant inhibition of conversion of AKT to PAKT in Ginkgetin treated cells as compared to Theaflavin treated cells after 24 hours of exposure and 24 hour of revival time. Band intensities were normalized against b-actin housekeeping protein as internal control.

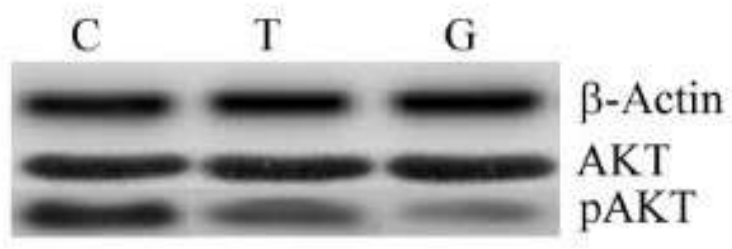

Figure 5. Western blot image showing relative abundance of AKT \& pAKT in Control(C), Theflavin treated $(T)$ and Ginkgetin treated $(G)$ cells.

\section{Angiogenesis inhibition assay}

Top panel depicts the original and magnified view of the embryo prior to the addition of Milli-Q water as control. Lower panel depicts 24 hrs post treatment. Both the embryos survived till 24hours in control group. 


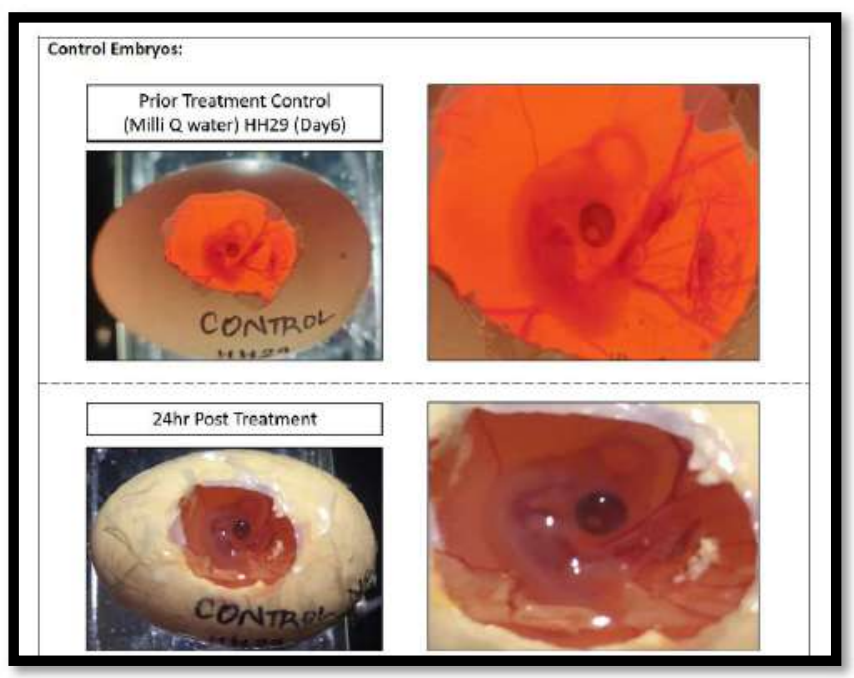

Figure 6(a): shows images of chick egg treated with MiliQ water.

Top panel depicts image before the treatment. Here arrows indicate Solid network of blood vessels. Top panel depicts the original and magnified view of the embryo prior to the addition of Theaflavin. Lower panel depicts 24 hrs post treatment effect. In this group the CAM was sunken and Haemorrhagic response was noted with constriction of blood vessels along with blood clotting all over the embryo.

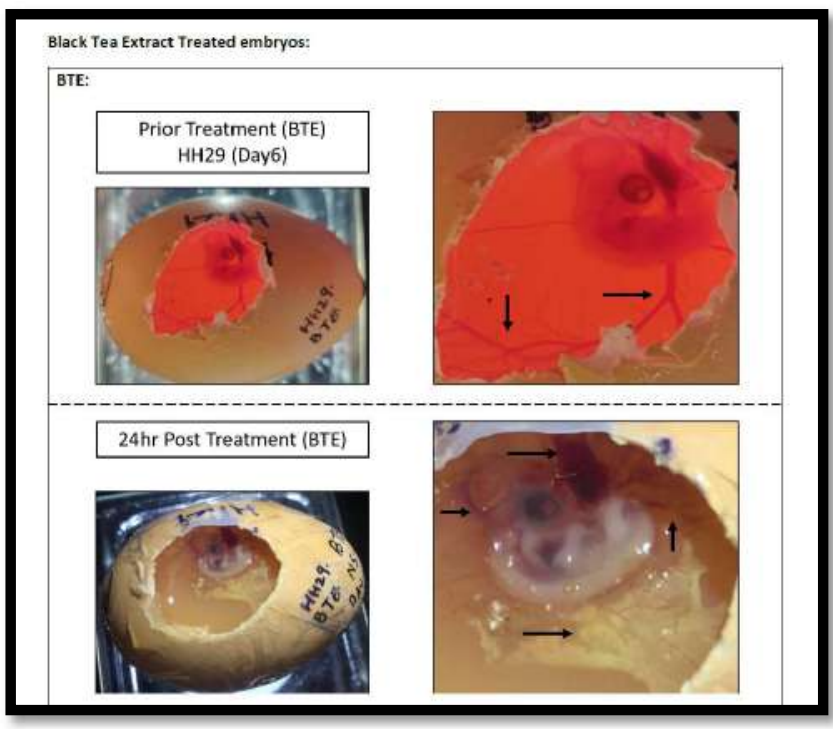

Figure 6(b): shows Chicken Embryos treated with Theaflavin.

Arrows indicate Solid network of blood vessels. Top panel depicts the original and magnified view of the embryo prior to the addition of Ginkgetin. Lower panel depicts 24 hrs post treatment 
effect. In this group the CAM was sunken and blood clotting observed near head, heart and near amniotic sac. The embryos did not survive suggestive of potent anti-angiogenic effect of Ginkgetin.

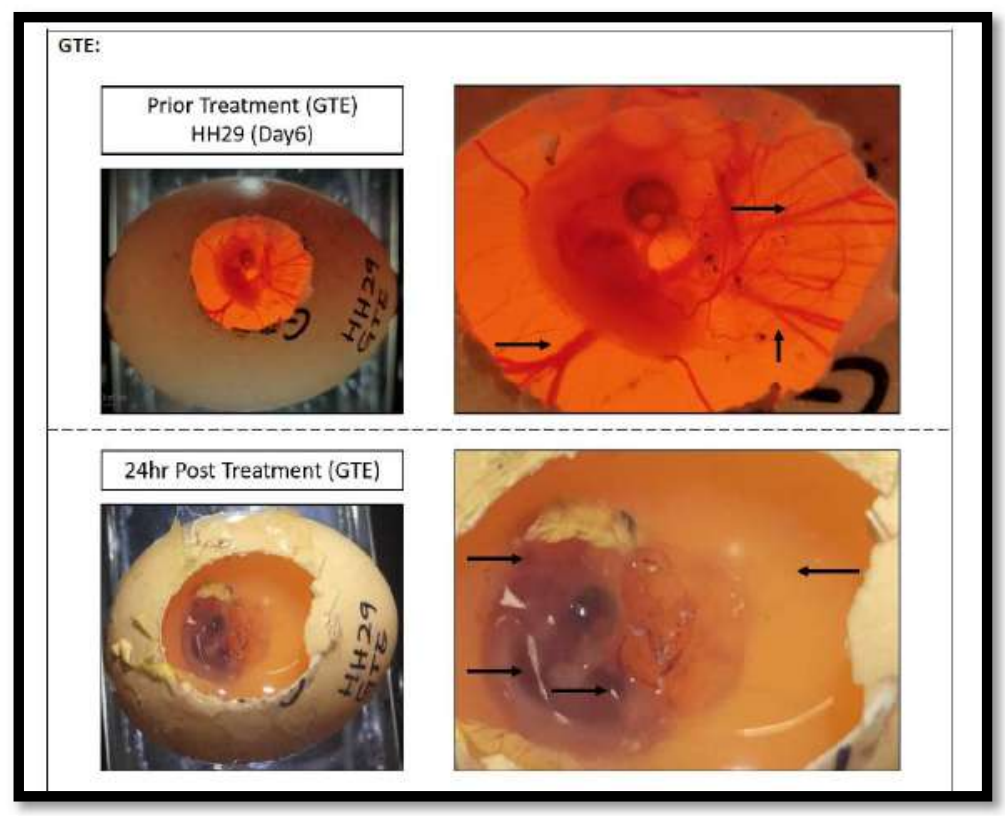

Figure 6(c): shows Chicken Embryos treated with Ginkgetin.

\section{DISCUSSION}

The c-MET receptor and its cognate ligand, hepatocyte growth factor (HGF), play key roles in orgnogenesis, homeostasis and wound healing. It is closely associated with $\mathrm{Wnt} / \beta$-catenin signaling, and promotes tumor proliferation, invasion, and metastasis by modulating this signaling pathway. C-MET/HGF binding also activates intracellular signal transduction pathways e.g. PI3K/AKT/mTOR and MAP kinase cascades, thus promoting cell proliferation, survival, morphogenesis and scattering (dissociation and motility). Aberrant activation of HGF/c-Met in colon cancer and glioblastoma, c-Met expression can enhance $\mathrm{Wnt} / \beta$-catenin signal transduction, and prevent GSK3 $\beta$ from phosphorylating $\beta$-catenin; this, in turn, promotes the translocation of $\beta$-catenin to the nucleus, facilitating tumorigenesis. Accordingly, it has been shown that c-Met inhibitors can inhibit Wnt pathway activity in tumor cells (Olalla LF et al, 2020). Phytochemicals were used for cure of so many diseases from the ancient times (Xiang $C$ et al, 2017). An analysis of the number of chemotherapeutic agents and their sources indicates that over $60 \%$ of approved drugs are derived from natural compounds. Many of the natural products such as taxel and vincristine are still in use for treatment of various cancer. Natural compounds 
work as anticancer agent with their involvement in different cellular pathways like cell cycle regulation, apoptosis induction, inhibition of angiogenesis, inhibition of invasion and metastasis, growth inhibition, anti-inflammation. (Pratheeshkumar $P$ et al, 2012) Several phytopharmaceuticals e.g. Hesperidin, silymarin, Epigallocatechin, gallate, curcumin, and capsaicin, which are obtained from dietary supplements reported to have cancer chemopreventive activity (Bindu D et al, 2019).

Ginkgetin is a natural bioflavonoid isolated from the leaves of Ginkgo biloba and is characterized by its anti-inflammatory and anti-viral activities (You KH et al, 2013). Although numerous studies state that it has also antitumor activities. It is a good STAT3 inhibitor, which has antiinflammatory, neuroprotective, anti-influenza virus and anti-fungal activities. It also works as a potent chemotherapeutic agent for prostate cancer treatment (Lou J et al, 2017).

Tea is one of the most popular beverages consumed in the world and has been demonstrated to have anti-cancer activity in animal models. Research findings suggest that the polyphenolic compounds, (-)-epigallocatechin-3-gallate found primarily in green tea, and theaflavin-3,3'digallate, a major component of black tea, are the two most effective anti-cancer factors found in tea. Several mechanisms to explain the chemopreventive effects of tea have been presented but others and this article suggest that tea components target specific cell-signaling pathways responsible for regulating cellular proliferation or apoptosis (Bhattacharya $U$ et al, 2011). Theaflavin is a class of natural flavonoids derived from the dried leaves of the plant Camellia sinensis (tea) and related plants with potent antioxidant properties. Theaflavins (TF) are antioxidant polyphenols that are formed from the condensation of flavan-3-ols in tea leaves during enzymatic oxidation of black tea. These molecules contain a tropolone moiety (Beltz LA et al, 2006; Wuqun T et al, 2016).

Natural product derived phytopharmaceuticals or nutraceuticals once thought to have only chemopreventive role now are being explored for their efficacy in tandem with cancer chemotherapeutics. This may be due to their reduced off-target toxicity or complementing the classical regimen making cancers more amenable to therapy. Present study suggests effectiveness of Ginkgetin and Theaflavin as potent modulator of cMET expressing cells and need further scientific exploration at in-vivo level before recommending them for patient supplementation. This may open up a new horizon of hope for the use of natural products, as mitigants of cancer, leading to a new frontier for natural product derived small-molecule based drug discovery. 


\section{References}

Alsaran EL, Morel HM, and Long W. Activation loop phosphorylation of ERK3 is important for its kinase activity and ability to promote lung cancer cell invasiveness. J. Biol. Chem.; 293, 16193-16205, 2018

Amaani R and Dwira S. Phytochemical content an in vitro toxicity of Glycine soja ethanol extract on the A549 Lung cancer line cell. Journal of Physics: Conf. Series 1073, 2018.

Andriani F, Perego P, Carenini N, Sozzi G and Roz L, Increased Sensitivity to Cisplatin in NonSmall Cell Lung Cancer Cell Lines after FHIT Gene Transfer1, Sensitization to Cisplatin after FHIT Gene Transfer, Neoplasia; 8(1): 9 - 17, 2006

Baylin SB and Jones PA. Epigenetic Determinants of Cancer. Cold Spring Harb Perspect Biol.; 8(9): a019505, 2016.

Beltz LA, Bayer DK, Moss AL, Simet IM. Mechanisms of cancer prevention by green and black tea polyphenols. Anticancer Agents Med Chem.; 6(5):389-406, 2006.

Bhattacharya U, Mukhopadhyay S, Giri AK. Comparative antimutagenic and anticancer activity of three fractions of black tea polyphenols thearubigins. Nutr Cancer.; 63(7):1122-32, 2011.

Chan $\mathrm{T}$ and Burggren W: Hypoxic incubation creates differential morphological effects during specific developmental critical windows in the embryo of the chicken (Gallus gallus). Respir Physiol Neurobiol.; 145:251-263. 2005.

Cruickshanks N, Zhang Y, Yuan F et al. Role and Therapeutic Targeting of the HGF/MET Pathway in Glioblastoma. Cancers; 9, 87, 2017.

Demkova, L., Kucerova, L. Role of the HGF/c-MET tyrosine kinase inhibitors in metastasic melanoma. Mol Cancer; 17: 26, 2018.

Elkhadragy, L, Alsaran, H., Morel, M., and Long, W., Activation loop phosphorylation of ERK3 is important for its kinase activity and ability to promote lung cancer cell invasiveness. J. Biol. Chem. 293, 16193-16205, 2018

Farnsworth RH, Lackmann M, Achen MG and Stacker SA. Vascular remodeling in cancer. Oncogene; 33, 3496-3505, 2014. 

Vyas \& Mr. Ram Tej Verma / Page 110-126

Fields WR, Desiderio JG, Putnam KP et al. Quantification of Changes in c-myc mRNA Levels in Normal Human Bronchial Epithelial (NHBE) and Lung Adenocarcinoma (A549) Cells following Chemical Treatment. Toxicological Sciences; 63(1): 107-114, 2001

Herbst RS: Targeted therapy using novel agents in the treatment of non-small-cell lung cancer. Clin Lung Cancer. 3(Suppl 1): S30-S38. 2002.

Herceg $Z$ and Hainaut P. Genetic and epigenetic alterations as biomarkers for cancer detection, diagnosis and prognosis. Mol Oncol.; 1(1): 26-41, 2007.

Hu X, Tang F, Liu P et al. Structural and Functional Insight Into the Glycosylation Impact Upon the HGF/c-Met Signaling Pathway. Front. Cell Dev. Biol.; 8:490, 2020

Khoogar R, Kim BC, Morris J et al. Chemoprevention in gastrointestinal physiology and disease.

Targeting the progression of cancer with natural products: a focus on gastrointestinal cancer, NATURAL PRODUCTS AND CANCER CHEMOPREVENTION, Am J Physiol Gastrointest Liver Physiol 310: G629-G644, 2016

Lambert AW, Pattabiraman DR, and Weinberg RA. Emerging biological principles of metastasis. Cell.; 168(4): 670-691, 2017.

$\mathrm{Li} \mathrm{J}$, Pan $\mathrm{YY}$ and Zhang $\mathrm{Y}$. Synergistic interaction between sorafenib and gemcitabine in EGFR-TKI-sensitive and EGFR-TKI-resistant human lung cancer cell lines, Oncology Letters; 5: 440-446, 2012

Lou J., Bi W., Chan G. K.L., Yan J., Wong C., Zhou Z., Wang H., Yao P., Dong T. T.X., Tsim K.W.K. Ginkgetin induces autophagic cell death through p62/SQSTM1-mediated autolysosome formation and redox setting in non-small cell lung cancer. Oncotarget.; 8: 93131-93148, 2017.

Olalla LF, Rubén D, Mirian P et al. Determination of Polyphenols Using Liquid ChromatographyTandem Mass Spectrometry Technique (LC-MS/MS): A Review, Antioxidants 2020.

Pratheeshkumar P, Sreekala C, Zhang Z et al. Cancer Prevention with Promising Natural Products: Mechanisms of Action and Molecular Targets, Published in final edited form as: Anticancer Agents Med Chem.; 12(10): 1159-1184, 2012.

Renzo MF, Narsimhan RP, Olivero M, Bretti S, Giordano S, Medico E, Gaglia P, Zara P, Comoglio PM. Expression of the Met/HGF receptor in normal and neoplastic human tissues. Oncogene; 11:1997-2003, 1991.

Ribatti D, Nico B, Vacca A et al. Chorioallantoic membrane capillary bed: a useful target for studying angiogenesis and anti-angiogenesis in vivo. Anat Rec.; 264:317-324. 2001. 
Ricci G, Catizone A, Galdieri M. Expression and functional role of hepatocyte growth factor and its receptor (c-met) during fetal mouse testis development. J Endocrinol; 191(3):559-70, 2006.

Robinson JP, Suriya K, Subbaiya R, Ponmurugan P. Antioxidant and cytotoxic activity of Tecoma stans against lung cancer cell line (A549), Braz. J. Pharm. Sci.;53(3):e00204, 2017

Tao W, Zhou Z, Zhao B, Wei T. Simultaneous determination of eight catechins and four theaflavins in green, black and oolong tea using new HPLC-MS-MS method, Journal of Pharmaceutical and Biomedical Analysis; 131: 140-145, 2016.

Toppmeyer DL, Gounder M, Much J, et al: A phase I and pharmacologic study of the combination of marimastat and paclitaxel in patients with advanced malignancy. Med Sci Monit.; 9:PI99-PI104. 2003.

Venepalli NK and Goff L. Targeting the HGF-cMET Axis in Hepatocellular Carcinoma. International Journal of Hepatology; 2013.

Vyas N, Pandya P, Mankad A, Verma R. Search For A Natural Antagonist Of Hepatocyte Growth Factor Receptor (Hgfr) Using Virtual Screening Approach. Life Science Informatics; 47(2454): 6348, 2019.

Wanda FR, Joseph GD, Kathy PP, David WB, David JD, Quantification of Changes in Cmyc mRNA Levels in Normal Human Bronchial Epithelial (NHBE) and Lung Adenocarcinoma (A549) Cells following Chemical Treatment, Toxicological Sciences, Volume 63, Issue 1, Pages 107-114, 2001.

Wang H, Rao B, Lou J, et al. The Function of the HGF/c-Met Axis in Hepatocellular Carcinoma, Front. Cell Dev. Biol.; 8:490, 2020.

Xiang C, Chen J and Fu P. HGF/Met Signaling in Cancer Invasion: The Impact on Cytoskeleton Remodeling, Cancers; 9: 44, 2017.

Yashin AY, Nemzer BV, Combet E \& Yashin YI. Determination of the Chemical Composition of Tea by Chromatographic Methods: A Review. Journal of Food Research; 4(3):887-895, 2015.

You KH, Kim SH, Kim B et al. Ginkgetin induces apoptosis via activation of caspase and inhibition of survival genes in PC-3 prostate cancer cells, Bioorganic \& Medicinal Chemistry Letters; 23(9):2692-2695,2013. 
Zhang $\mathrm{Y}$, Mengfang Xia M, Ke Jin $\mathrm{K}$ et al. Function of the c-Met receptor tyrosine kinase in carcinogenesis and associated therapeutic opportunities, Molecular cancer; 56, 2018

Zhou Q, Qi CL, Li Y et al. A novel four-step system for screening angiogenesis inhibitors, Molecular Medicine Reports; 8: 1734-1740, 2013.

\author{
Mr. Nisarg Vyas \\ Research Scholar \\ Department of Zoology, University School of Sciences, \\ Gujarat University, Ahmedabad \\ \& \\ Mr. Ram Tej Verma \\ Professor \& Head \\ Department of Zoology, Human Genetics and BMTC \\ Gujarat University, Ahmedabad
}

